\title{
Selective Extrapontine Myelinolysis in Osmotic Demyelination Syndrome in a Case of Previously Undiagnosed Sheehan's Syndrome with Recurrent Hyponatraemia - A Rare Association
}

\author{
FM SI DDI QUI , ${ }^{1}$ MD. MAHMUDUR RAHMAN SIDDI QUI , ${ }^{2}$ MD. AZHARUL HOQUE, ${ }^{3}$ SAEEDUR RAHMAN SHUJ ON ${ }^{4}$ \\ AHMED HOSSAIN ${ }^{5}$
}

\begin{abstract}
:
Selective extrapontine myelinolysis (EPM) following a marked change in osmolarity, usually due to the rapid correction of hyponatraemia. Association of EPM in hyponatraemia from Sheehan's syndrome is very rare. We report a 38 years old lady with EPM, who presented with repeated attacks of hyponatraemia for 2 years, which were corrected several times after hospital admissions. She has got history of postpartum haemorrhage about 10 years back followed by secondary amenorrhoea and lactational failure. At present she came to us with features of parkinsonism, dystonia, mutism, insomnia and emotional outburst. Her magnetic resonance imaging (MRI) of the brain revealed features of myelinolysis with atrophied pituitary gland. Her serum pituitary hormonal levels confirm presence of hypopituitarism with secondary adrenal failure due to Sheehan's syndrome. Now her present features are due to selective extrapontine myelinolysis of osmotic demyelination, might be due to any episode of inappropriate intravenous correction of hyponatraemia.
\end{abstract}

Keyword: Sheehan's syndrome, Hyponatraemia, Extrapontine myelinolysis, Osmotic demyelination syndrome

\section{Introduction:}

Osmotic demyelination syndrome (ODS) refers to central pontine myelinolysis (CPM) and/or extra-pontine myelinolysis (EPM) following a rapid marked change in osmolarity, usually due to the rapid correction of hyponatraemia of any cause. ${ }^{1}$ In the past, ODS gained attention only as a rare pathology and was observed only during autopsies. With the aid of modern imaging techniques, most notably magnetic resonance imaging (MRI), a wide range of patient have been identified, though it is very rare. ${ }^{2}$ Our patient presented with repeated hyponatraemia for 2 years followed by features of ODS. To evaluate the cause of repeated hyponatraemia we have found that, she was suffering Sheehan's syndrome which was undiagnosed previously. Sheehan's syndrome with Osmotic demyelination syndrome (extrapontine) is a very rare association. This reminds us that caution is essential in dealing with any case of hyponatraemia to avoid life threatening ODS with an inquisitive search to find the actual cause of hyponatraemia.

\section{Case report:}

A 38-year-old teacher presented to us with a 15 days history of generalized stiffness and difficulty in opening her mouth which was preceded by several episodes of vomiting. She also became emotionally labile with occasional outburst mainly at night with mutism and insomnia. Initially she was admitted at local health facility with recurrent vomiting and she was diagnosed to have electrolyte imbalance and was treated accordingly. Later she developed the stiffness but as she was not much improved, was referred to our hospital (Dhaka medical college hospital). On inquiry her husband stated that she had an episode of fever about 2 yrs back where she developed alteration of consciousness without any lateralizing signs, convulsion. And subsequently was diagnosed as a case of encephalitis. Following treatment she apparently made full recovery within 15 days. Over the next $1 \frac{1 / 2}{2}$ rs she experienced several episodes of vomiting and electrolyte imbalance. She has been amenorrhoeic for 10 years since the birth of her last child during which she had an episode of post partum haemorrhage where also associated lational failure was there. General examination revealed patient assuming a flexed posture with stable vitals and no postural drop. Pubic and axillary hairs were sparse. Neurological examination revealed gross disorientation, mostly at night, with emotional outburst. Her speech was

1. Chief Scientific Officer, Institute of Epidemiology, Disease Control and Research (IEDCR), Dhaka, Bangladesh.

2. FCPS (Medicine) course, Department of Medicine, Dhaka Medical College.

3. Associate Professor, Department of Neurology, Dhaka Medical College,

4. Registrar, Square Hospital, Dhaka, Bangladesh.

5. Assistant Professor, Department of Medicine, Dhaka Medical College,

Correspondence: Dr. Md. Mahmudur Rahman Siddiqui, FCPS (Medicine) course, Department of Medicine, Dhaka Medical College. Email: dr.mahmud99@yahoo.com 


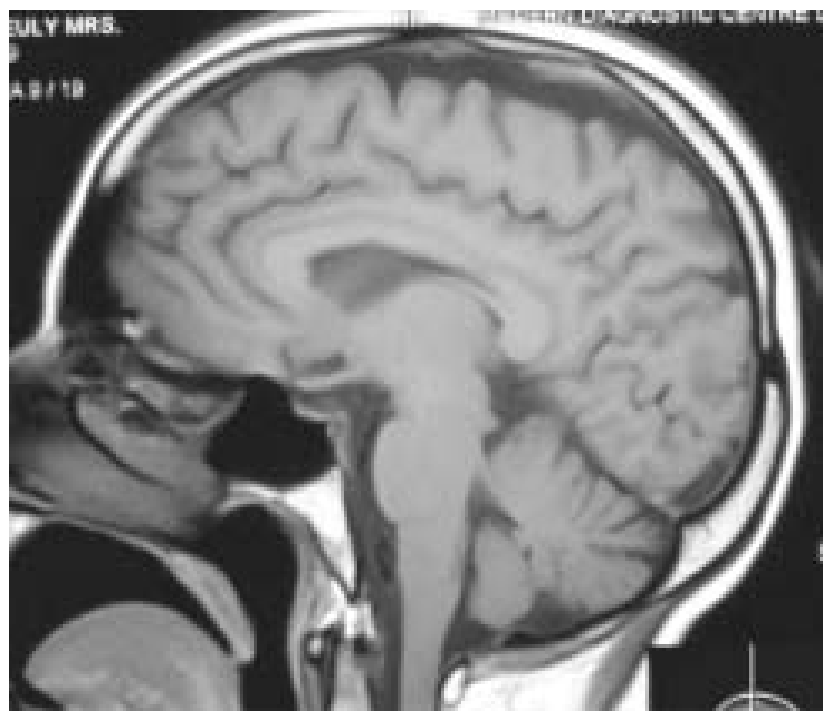

Fig.-1: Sagital plan T1 weighted MRI of brain showing very small atrophied pituitary gland.

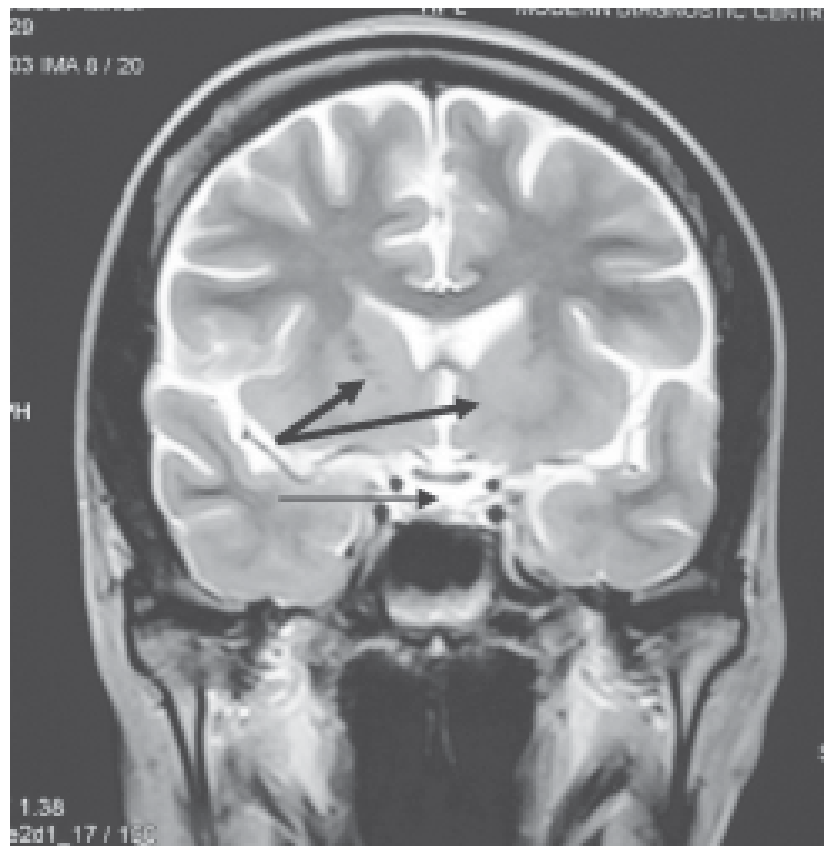

Fig.-2: Coronal plan T2 weighted MRI of brain showing empty sella (thin arrow) as evidence by sella is occupied by hyperintense CSF. There is also bilateral hyperintense caudate nucleus (thick arrow).

dysarthric. Restricted examination of cranial nerves including both fundus (as the patient was non compliant) revealed normal findings. Rigidity was present in all four limbs, with orofacial dystonia and dystonic posture of hands and feet, with tremor in both hands. There was no muscle wasting or fasciculation. Muscle power could not be evaluated. All deep tendon reflexes were normal with bilateral flexor planter

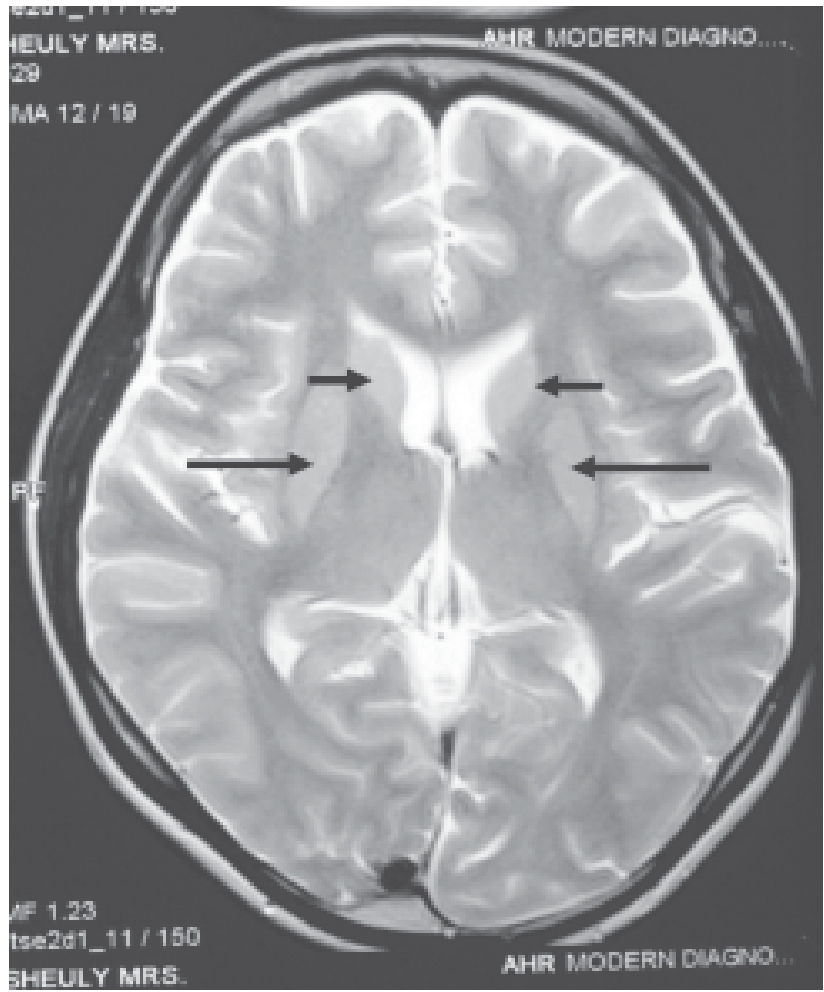

Fig.-3: T2 weighted MRI of brain showing hyperintensity of bilateral basal ganglia (arrows).

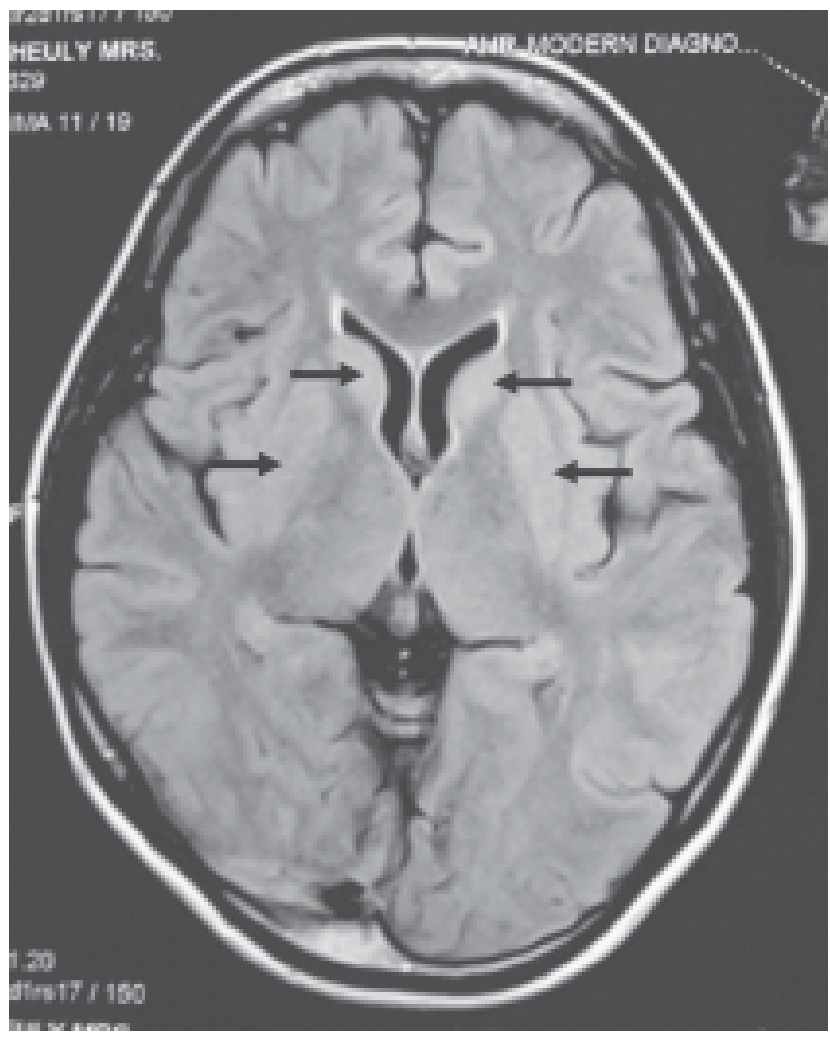

Fig.-4: FLAIR weighted MRI of brain showing hyperintensity of bilateral basal ganglia (arrows). 
response . Sensory system, sign of meningeal irritation, cerebellar sign and gait could not be evaluated.

Investigations revealed normal findings on most routine investigations. Her serum electrolytes revealed $\mathrm{Na}^{+}: 120$ $\mathrm{mmol} / \mathrm{l}, \mathrm{K}^{+}: 5.44 \mathrm{mmol} / \mathrm{l}, \mathrm{Cl}^{-}: 79 \mathrm{mmol} / \mathrm{l}, \mathrm{HCO}^{-}: 22.7 \mathrm{mmol} / \mathrm{l}$. Her seum urea: $25.4 \mathrm{mg} / \mathrm{dl}$ and serum creatinine: $0.9 \mathrm{mg} / \mathrm{dl}$. On her hormone profile serum follicular stimulating hormone (FSH): $3.85 \mathrm{mIU} / \mathrm{ml}$, serum luteinising hormone (LH): $10 \mathrm{mIU} /$ ml, serum Estradiol: 178 pg/ml, serum Prolactin: $10.66 \mathrm{ng} / \mathrm{ml}$, Basal cortisol: $574.56 \mathrm{nmol} / \mathrm{l}$, Thyroid function test: S. FT3 : $2.23 \mathrm{nmol} / \mathrm{l}, \mathrm{S}$. FT4: $68.47 \mathrm{nmol} / \mathrm{l}, \mathrm{S}$. TSH: $2.68 \mathrm{mIU} / \mathrm{l}$ (All were lower normal ranges). Her CSF study revealed normal findings as well. Magnetic resonant image (MRI) of the brain showed normal T1 weighted images, but in T2 and FLAIR weighted images there were bilateral symmetrical hyperintensity of the basal ganglia, putamen and there was also atrophied very small pituitary gland (Figs 1,2,3,4). So, we diagnosed her as a case of Sheehan's syndrome with selective extrapontine osmotic demyelination syndrome. She was put on steroid, levodopa, carbidopa, Procyclidine. She improved significantly. Steroid dose was tapered and known she is on maintenance without any new episodes of hyponatraemia. Within 8 months she was back to her teaching profession $\&$ is on regular follow up with us.

\section{Discussion}

Central nervous system is vulnerable to rapid osmotic changes. Osmotic demyelination syndrome (ODS) is a complication of treatment of patients with severe and prolonged hyponatraemia (usually $<120 \mathrm{mEq} / \mathrm{l}$ ), particularly when corrected too rapidly. ${ }^{3}$ This was first recognized by Tomlinson in $1976 .{ }^{4}$ The exact incidence of osmotic demyelination syndrome is unknown. Common conditions associated with an increased risk of the syndrome include chronic alcoholism, malnutrition, prolonged diuretic use, liver failure, recepicent of organ transplant, and extensive burns. 5 But our patient was suffering from chronic repeated hyponatraemia due to Sheehan's syndrome, which is a very rare association. In Worldwide only a few cases were reported.

6 Hyponatraemia can be the presenting manifestation of Sheehan's syndrome. ${ }^{6}$ It can be chronic or may appear in the early post-partum period. ${ }^{6} \mathrm{ADH}$ is known to play a role in the pathogenic mechanism. However, the cause of ADH secretion in hyponatraemia associated with hypopituitarism is related to adrenocortical insufficiency. ${ }^{7}$ The glucocorticoid deficit is not an osmotic but a physiological stimulus for ADH secretion. ${ }^{6}$ Glucocorticoids have been shown to reverse the impaired water diuresis of this disorder by increasing the renal excretion of solute free water. ${ }^{6}$ Thus, glucocorticoid substitution has been the mainstay treatment of hyponatraemia associated with hypopituitarism. ${ }^{6}$
Adams and colleagues first described central pontine myelinolysis as symmetrical, non-inflammatory demyelination in the pons in $1958 .^{5}$ Extrapontine myelinolysis, with or without pontine involvement, was recognized in 1962 although both conditions share the same pathology. ${ }^{8}$ Hyponatraemia below $120 \mathrm{mEq} / \mathrm{l}$ causes symptoms related to brain edema; weakness, headache, nausea, vomiting, vertigo, irritability, seizure and lack of consciousness. ${ }^{3}$ Our patient repeatedly presented with nausea, vomiting, vertigo, depressed consciousness for 2 years, due to repeated hyponatraemia. Clinical presentations of ODS are depending on the site of lesions in brain. Classically, central pontine myelinolysis is associated with dysarthria and dysphagia, due to corticobulbar fibre involvement, as well as an initially flaccid quadriparesis due to lesions in the corticospinal tract. ${ }^{5}$ Extrapontine myelinolysis is characterized by movement disorders including tremor, ataxia, mutism, parkinsonism, dystonia, and catatonia. ${ }^{5,9}$ In patients with central pontine and extrapontine myelinolysis, the clinical features of extrapontine involvement are rarely seen, because they are masked by the symptoms of pontine involvement. ${ }^{1}$ But our patient presented to us with the features of only movement disorders like parkinsonism, dystonia due to selective extrapontine myelinolysis. In recent years it have been published that parkinsonism is the most prominent features of extrapontine myelinolysis. ${ }^{9}$ The behavioral manifestations preceding the onset of Parkinsonism were first reported by Dickoff et al. and were similar to those reported in our case. Acute stage may present in confusion, insomnia, irritability, abnormal behavior, psychosis to coma and death. ${ }^{10}$

Brain imaging is the most useful diagnostic test for ODS and an MRI is more sensitive. ${ }^{1}$ But myelinolytic lesions may not be apparent on scans during the first 2 weeks of illness. ${ }^{1,2}$. Hyper intense shadows in T2 and FLAIR weighted images of MRI are found in pons and bilateral other extrapontine sites like; putamen, caudate nuclei, lateral thalamus and cortical laminar necrosis. ${ }^{1,2}$ Empty sella or atrophied pituitary can be detected in Sheehan's syndrome. ${ }^{6}$ All other test except serum electrolytes should be normal in ODS. But association of Sheehan's syndrome can be explained by low serum level of various pituitary hormones. In our patient most of these hormones were in lower normal ranges. A patient with pituitary insufficiency sometimes can maintain basal ACTH and/or basal concentrations of serum cortisol, but which failed to increase or maintain basal level during stress or on demand more. ${ }^{11}$ For these reasons dynamic function tests should be performed when there is confusion. ${ }^{11}$ In our patient with single normal basal cortisol can be explained by these and other advanced test could not be performed due to financial problem of the patient. 
The outcome of patients with myelinolysis varies, ranging from complete recovery to death. ${ }^{1}$ There is no specific treatment for myelinolysis but symptomatic treatment (dopaminergic drug) and prolonged neuro-rehabilitation for movement disorders. ${ }^{1,5}$ Glucocorticoid substitution has been the main treatment of hyponatraemia associated with hypopituitarism. ${ }^{6}$ Subsequent follow up should be taken to find out any other hormonal deficiency. If hyponatraemia is present it is important to correct this slowly, at a rate of less than $8 \mathrm{mmol} / \mathrm{l} /$ day to minimize the risk of developing ODS. ${ }^{5}$

\section{Conclusion:}

Hypopituitarism including secondary adrenal insufficiency seems to be a frequently overlooked cause of repeated severe hyponatraemia. A high level of suspicion is the best way to recognize the underlying disorder. Parkinsonism may be the most prominent feature of extrapontine myelinolysis with a good clinical outcome after dopaminergic treatment. MRI is essential tool for the diagnosis, but does not necessarily correlate with the clinical picture. Judicial treatment of hyponatraemia is the only way to prevent ODS.

\section{Conflict of Interest: None}

\section{References:}

1. Koussa S, Nasnas R. Catatonia and parkinsonism due to extrapontine myelinolysis following rapid correction of hyponatraemia. J Neurol 2003; 250: 103-5

2. Hagiwara K, Okada Y, Shida N and Yamashita Y. Extensive Central and Extrapontine Myelinolysis in a Case of Chronic Alcoholism without Hyponatraemia: A Case Report with Analysis of Serial MR Findings. Inter Med 2008; 47: 43135
3. Shoji M, Kimura T, Ota K, Ohta M, Sato K, Yamamoto T, Funyu T, Mori T, Tateyama M and Abe K. Cortical laminar necrosis and central pontine Myelinolysis in a patient with sheehan syndrome and severe hyponatraemia. Internal Medicine 1996;35: 427-31

4. Tomlinson BE, Pierides AM, Bradley WG. Central pontine myelinolysis: two cases with associated electrolyte disturbance. Q J Med 1976;45:373-86

5. Abbott R, Silber E, Felber J, Ekpo E. Osmotic demyelination syndrome. BMJ 2005;331:829-30

6. Lee WC, Cheng YF, Chen JB. Treating hyponatremia in an empty sella syndrome patient complicated with possible myelinolysis. Chang Gung Med J 2002;25:838-43

7. Wakui H, Nishinari T, Nishimura S, Endo Y, Nakamoto Y, Miura AB. Inappropriate secretion of antidiuretic hormone in isolated adrenocorticotropin deficiency. Am J Med Sci 1991;301:319-21

8. Martin RJ. Central pontine and extrapontine myelinolysis: the osmotic demyelination syndromes. J Neurol Neurosurg Psychiatry 2004;75(suppl 3): iii22-8

9. Seiser A, Schwarz S, Steiner MMA, Funk G, Schnider P, Brainin M. Parkinsonism and dystonia in central pontine and extrapontine myelinolysis. J Neurol Neurosurg Psychiatry 1998;65:119-21

10. Dickoff D, Rapps M, Yahr M. Striatal syndrome following hyponatraemia and its rapid correction: a manifestation of extrapontine myelinolysis confirmed by magnetic resonance imaging. Arch Neurol 1988;45:112-14

11. Lynnette KN, Andre L, Kathryn AM. Evaluation of the response to ACTH in adrenal insufficiency. Uptodate feb 13, 2008. http://www.uptodate.com/patients/content/ topic.do?topickek 